Article

\title{
Implications and Measurement of Energy Poverty across the European Union
}

\author{
Alexandru Maxim ${ }^{1,+}$, Costică Mihai ${ }^{2, \dagger}$, Constantin-Marius Apostoaie ${ }^{1,+}$, Cristian Popescu ${ }^{2, \dagger}$, \\ Costel Istrate ${ }^{2,+}$ and Ionel Bostan $3, *,+$ \\ 1 CERNESIM Environmental Research Center, Alexandru Ioan Cuza University of Iasi, Str. General Berthelot 16, \\ 700483 Iasi, Romania; maxim.alexandru@uaic.ro (A.M.); marius.apostoaie@uaic.ro (C.-M.A.) \\ 2 Faculty of Economics and Business Administration, Alexandru Ioan Cuza University of Iasi, Blvd. Carol I 11, \\ 700506 Iasi, Romania; ticu@uaic.ro (C.M.); popescu@uaic.ro (C.P.); istrate@uaic.ro (C.I.) \\ 3 Doctoral School of Economics, Stefan cel Mare University of Suceava, Str. Universitatii 13, \\ 720229 Suceava, Romania \\ * Correspondence: ionel_bostan@yahoo.com; Tel.: +40-0230-216-147 \\ + These authors contributed equally to this work.
}

Academic Editor: Marc A. Rosen

Received: 4 April 2016; Accepted: 9 May 2016; Published: 16 May 2016

\begin{abstract}
Energy poverty, or the inability of households to afford adequate access to energy services, is an issue that can have a significant effect on the quality of life and even the state of health of individuals and even the overall development of a nation. Since it was first brought into focus more than two decades ago in the UK, this topic has gradually gained the attention of academics and policy makers all across the EU and beyond. The current paper addresses the topic by providing not only a renewed discussion, but also an improved energy poverty indicator (with clear and relevant results at the EU level): the Compound Energy Poverty Indicator (CEPI). Moreover, knowing that the risk of poverty and social exclusion, efficiency of heating systems, total consumption of energy per household and rising energy prices tend to increase the severity of this problem in some countries, CEPI is then included into an econometric model so as to determine some possible factors that tend to put pressure on an already existing issue of energy poverty. The results of this research are expected to be relevant not only for academics (as it offers insights into the structure and severity of this topic within the European Union), but also for national and EU policymakers who are confronted in the field with the problem of sustainable development.
\end{abstract}

Keywords: energy poverty; sustainability; Compound Energy Poverty Indicator; European Union

\section{Introduction}

Energy poverty (EP) is a term that can refer to two types of social inequalities, depending on the geographic sphere of its application. In the EU context, energy poverty is also known as "fuel poverty", although the meanings of the two terms are slightly different. It refers to a socio-economic issue that is distinct from "poverty" in the traditional sense, in that it is generated by households needing to spend a disproportionately high share of their income on energy services. In developing countries, it covers aspects such as households' lack of access to energy services such as electricity, the use of outdated technologies or the use of hazardous or inefficient fuels for providing homes with the energy needed for cooking, heating and lighting (e.g., burning firewood and other traditional biomass for cooking and heating).

The current paper addresses energy poverty in the EU context. The term "fuel poverty" seems to have originated in the late 1970s with several mentions of this term referring to households that have disproportionately high fuel expenditures compared to the rest of the population [1]. An extensive 
discussion on the topic and definition of the term was conducted by Boardman [2] in a book that had a significant impact on the UK Fuel Poverty Strategy of 2001. Many researchers agree that the primary factors which exert a certain pressure on the existence of fuel poverty are low incomes, rising energy prices and, in particular, the low quality of the housing stock (poor insulation, leaking roofs, low quality door and window frames that allow drafts to form, etc.).

Given that the extensive work performed by Boardman in this emerging field of research was focused on the United Kingdom (UK), it seemed that the issue of fuel poverty was endemic to this country [3]. Indeed, for a long period of time, the United Kingdom and the Republic of Ireland remained the only EU member states where this problem was both recognized and systematically addressed by means of household support policies and energy efficiency investments [4].

Low awareness of the problem as well as differing academic and political concerns compared to the UK meant that research and policy measures across the rest of Europe were practically non-existent. However, over the last few years, the issue has gained gradual recognition in several other EU states and even in the official documents of some EU institutions. Bouzarovski et al. state that the concept of fuel or energy poverty "has crept into a number of regulatory documents and policy proposals" ([5], p. 76) due to the slow and precarious rate at which this issue gained recognition across Europe.

Today, there is growing interest in adequately defining, measuring and addressing this issue within the EU, but studies on this topic outside of the UK and Ireland is still limited. Specialists in the field seem to be in agreement that continued academic support and research is needed in order to efficiently tackle this socio-economic problem [4,6-9]. Several researchers have argued in favor of adopting national or regional measures to address energy poverty due to the specific issues and needs that exist in each member state (e.g., climate, household ownership, structure of the housing stock, and type of heating services or appliances). Moreover, there are few studies that have assessed the specific factors contributing to energy poverty in post-communist countries in Eastern Europe. Some of these include: inefficient district heating networks [10,11], significant increases in costs after market liberalization and unbundling of energy companies (due to the elimination of state regulated tariffs, increases in transmission and distribution costs, and the consolidation of oligopolies) [12-14].

This paper aims to provide a renewed discussion on the topic of energy poverty at the EU level, but also an improved energy poverty indicator. Moreover, the paper looks into the possible factors that could put pressure on an existing situation of energy poverty. The results of this research are expected to be relevant not only for the existing literature (as it offers insights into the structure and severity of this topic within the European Union), but also for national and EU policymakers who must deal in practice with the issue of energy poverty.

The current work extends and improves the existing research on the topic of energy poverty in several aspects:

- Until recent years, quantitative insights regarding EP existed only in the case of the UK and Ireland. The current study is able to provide an explicit image of energy poverty (as determined by the hereby proposed CEPI) for every EU member paving the way for future similar endeavors.

- We offer an improved energy poverty indicator which, in addition to the variables used by Tirado Herrero and Bouzarovski in constructing their "energy poverty index" (i.e., arrears on utilities, poor dwelling quality and the self-assessed inability to maintain the home adequately warm), includes two more variables that are also self-assessed and directly related to EP (dwellings not comfortably cool during summer time and dwellings too dark). Thus, CEPI is more fine-tuned to the conceptual definition of energy poverty, provides a more complete picture and is more likely to detect some of the subtleties that the previous indicator may have missed. The usage of Eurostat data provides methodological consistency and a European focus, making CEPI very useful in performing country comparisons and presenting evolutions over time (compared to the already existing energy poverty index which was expressed only in correlation with other factors and not independently).

- We propose a prediction model of energy poverty based on factors that are likely to put pressure on an already existing situation of EP. After performing a correlation analysis between CEPI 
and six initial pressure factors, a multiple linear regression was performed to identify the two most relevant variables that proved to have a greater impact on energy poverty (as determined by CEPI), namely "People at risk of poverty or social exclusion" and "Affordability of energy". Among the six initial pressure factors that were considered in the analysis two were specifically calculated, three were selected and extracted from existing European data sources and one was computed using a more sophisticated approach based on the researchers' experience.

- We propose a compound indicator that is able to express the average affordability of energy at the national level (as impacted by income and energy prices). This indicator can be useful in research on other topics that involve cross-country comparisons.

In Section 2, the paper seeks to offer an understanding of the relationship between energy poverty and sustainability following concrete steps: unpacking the terminology and definitions on the subject, highlighting sustainability implications of fuel poverty and revealing policy responses from governments across the EU. Section 3 of the paper looks into methods used in measuring energy poverty in the EU member countries and provides a quantitative analysis on the topic. Within this section, after a brief introduction into the subject and a short description of the existing proxy indicators, the paper proposes an improved instrument for assessing energy poverty entitled Compound Energy Poverty Indicator (CEPI). It then determines and evaluates the factors that tend to put pressure on an already existing situation of energy poverty. The final section is dedicated to conclusions, discussions and future directions of research.

\section{Understanding the Relationship between Energy Poverty and Sustainability}

\subsection{Terminology and Definition}

As mentioned in the Introduction, the term "energy poverty" can refer to two different socio-economic issues, depending on the geographical scope of its application: energy affordability in higher income and developed states; inadequate access to "modern" energy services in most low income or developing countries. Bouzarovski [4] mentions the existence of a separate category of studies focused on the developing world that discuss "energy poverty" in a different sense than that used in the current paper. In fact, this distinction can be directly observed both in academic research papers and reports on the topic [7,15-18]. It is estimated that around 100 million people are affected by energy poverty in Europe [19], and that close to 1.2 billion people worldwide do not have access to electricity [20]. Given that both types of energy poverty have a wide and lasting impact on the population, they are expected to remain important topics of research for the foreseeable future.

In addition to the double meaning of "energy poverty", further lack of clarity results from the use of a wide terminology to refer to the same essential issue. As mentioned previously, the issue of "energy poverty" initially emerged under a different name- "fuel poverty" — which has a slightly different meaning ("principally seen as the inability to purchase affordable warmth" [4]). Bouzarovski [4] also identifies other expressions used for the same purpose, such as "domestic energy deprivation" or "energy precariousness". Thus, researchers approaching this topic should be aware of these terminology issues and of the precise policy implications of each term (e.g., a working paper by the European Commission clearly distinguishes fuel poverty as having a broader scope compared to energy poverty from a legislative perspective [21].

With regard to actually defining the problem, Isherwood and Hancock [22] are cited as being among the first to define "households with high fuel expenditure as those spending more than twice the median (i.e., 12\%) on fuel, light and power" ([23], p. 368), where the median refers to the fuel expenditure of UK households.

Social and cultural norms can also have an impact on how people evaluate and define desirable or normal behavior. The fact that the manifestation and the severity of fuel poverty can be influenced by such norms was evidenced in the definition provided by Bradshaw and Hutton [24]: 
"Individuals, families and groups in the population can be said to be in fuel poverty when they lack the resources to obtain the reasonably warm and well lit homes which are customary, or at least widely encouraged or approved in the societies to which they belong." ([1], p. 27)

A widely discussed and accepted definition, which was also adapted and put into practice for the purpose of measuring fuel poverty in the UK as well as in other countries, was provided by Boardman [2]. Households in this situation were considered to be those who spent more than $10 \%$ of their income on all energy services. This was also based on a "twice the median expenditure" threshold for fuel as seen in the case of Isherwood and Hancock [22].

However, a risk of underestimating the problem exists when taking into consideration only households that actually spend more than the established threshold. This is because people who find it difficult to afford an adequate energy supply may decide to restrict their consumption by only heating or lighting one room or lowering the overall temperature in the home. By limiting their expenditure on energy, such households could fall outside of the " $x \%$ of income" definition. It is for this reason that the definition used by UK policymakers takes into consideration households that need to spend more than $10 \%$ of their income on energy services. Maintaining the definition in its initial form would likely provide a conservative estimation of the extent of the phenomenon.

As more studies on this topic emerged, the complexity of the problem made establishing a widely accepted definition of fuel poverty very challenging. In order to increase the precision of the definition, several adjustments or alternatives were proposed, including the exclusion of housing costs from income, the use of equivalized incomes, the use of budget standards or the use of household expenditure rather than income. A well-known proposal is that of John Hills, which considers households to be fuel poor if their required fuel costs are above the national median and if spending that amount would result in a residual income (after housing costs) that is below the official poverty line [25].

However, such revisions mainly seek to outline an adequate methodology for measuring energy poverty and will be discussed further in the following sections. In order to conclude the current subsection, we propose that the concept of energy poverty can be correctly outlined using the definition provided by Bouzarovski: "a situation in which a household lacks a socially and materially necessitated level of energy services in the home" ([4], p. 276).

\subsection{Sustainability Implications of Fuel Poverty}

In a world that is constantly evolving, energy represents the foundation of development. However, related to the everyday use of energy, two issues related to energy poverty are frequently observed in political speeches and scientific research:

- Problems related to energy access, regardless of its form; this issue is specific to areas of the globe that are economically poor and lack the necessary energy resources as well as the means to utilize them.

- Problems related to costs and efficient use within developed areas.

Considering that the increase in the level of energy use in both of the above mentioned regions, it becomes highly relevant to discuss the how it is produced, what economic results it generates, as well as what impact it has on the environment and the society. Within this context, analyses focused on various fields of specialization have revealed that: "A reliable energy source is a prerequisite for sustainable development and poverty alleviation, and the Millennium Development Goals cannot be achieved without first addressing energy issues." [26].

Energy use can be seen as the origin of several important factors that influence sustainable development:

- Firstly, with regard to its production, "clean" renewable energy (with limited adverse effects for the environment and human health) is a key component of sustainability $[27,28]$. 
- A more efficient use of energy through the development and incorporation of new technologies leads to a reduction in costs and an increase in the standard of living [29].

- The constantly growing needs of the population can only be met by identifying new and plentiful energy sources; the increase in availability sets the groundwork for the improving the use of the labor force by creating new employment opportunities and increasing wages, leading to a higher quality of life. The impact of the developments in the energy sector on employment has been analyzed in various studies at the European and global level. For example, the study performed by Markandya, et al. [30] reveals the high impact of the "energy and gas sectors" on the labor force (with 65,000 jobs created during 1995-2009). In addition to the quantitative effects, some studies also highlight some qualitative aspects. For example, the European Foundation for the Improvement of Living and Working Conditions [31] noticed that the sectors which will have the highest impact on the development of skills are the construction and energy sectors.

Previous studies have used both quantitative and qualitative methods to assess the physical, psychological and social implications of energy poverty. This section will seek to outline some of the key findings in order to raise awareness regarding the effects and the significance of this problem that affects large portions of the population in high and middle income states.

The most obvious impact of energy poverty is on the physical and mental wellbeing of the affected households' members. Boardman's own research acknowledges the fact that the United Kingdom recorded an unusually high number of deaths during the cold seasons compared to other regions that have harsher winters. This was partly associated with low indoor temperatures [32]. A report by the World Health Organization (WHO) states that over 38,000 excess winter deaths per year in 11 European are related to low indoor temperatures [33]. This suggests that a portion of the population is unable to afford adequate warmth, which supports the use of the "need to spend" rather than actual expenditures when defining fuel poverty. In addition to the health problems directly associated with cold temperatures, these can also be associated with indoor dampness and mold [34] —living conditions that can generate additional complications for the inhabitants.

However, most research only discusses the adverse health effects of low indoor temperatures, while certain areas of Europe are also prone to hazardously high temperatures during the summer. The WHO recommendation regarding air temperatures in the home is $18-24{ }^{\circ} \mathrm{C}$ [35], a range that is often exceeded in Southern and South-Eastern Europe in the case of homes that are not equipped with air-conditioning. Some chronically ill and elderly people are especially vulnerable to excess heat. Thus, any assessment of the energy needs for households should also take into consideration the cost of keeping homes cool during the summer. Pye, et al. [36] are also in favor of using this type of indicator in energy poverty studies given that "Southern European Countries have been experiencing frequent heat wave events in the summer time which seem to be responsible for mortality rate growth among low income households and vulnerable people".

A study by Brunner, Spitzer and Christanell [19] showed that those energy poor households which do make an effort to supply their home with an adequate amount of energy may choose to cut back on other expenses, including food, an option that can generate other types of adverse health effects.

With regard to mental wellbeing, other studies mention the stress caused by receiving the invoice for the energy bill (which may be unaffordable if it exceeds a certain amount), the prospect of being disconnected from the utilities, and news regarding the increase of energy prices [19]. In addition, it can be hypothesized that the need to resort to different coping strategies such as partial heating and lighting, the purchase of second-hand products, and not taking full baths can also contribute to depression.

Energy poverty can be particularly difficult to identify in certain cases due to the socially undesirable prospect of being classified as "poor". Some researchers mention the fact that some households make an effort to hide their difficulties from visitors (by making their homes bright and warm before someone arrives) and perceive the idea of being identified as "fuel poor" to be stigmatizing $[6,19]$. Social exclusion is also likely to be an indirect consequence of energy poverty, as 
households may begin to avoid inviting guests frequently due to the increased energy consumption entailed by an upcoming visit.

\subsection{Policy Measures in the Area of Fuel Poverty}

Directives 2009/72/EC and 2009/73/EC of the European Parliament and the Council [37,38], which refer to the common rules for the internal market in electricity and natural gas supply are the first to explicitly mention energy poverty and recommend that each member state adopt measures to alleviate this problem. The concept of "vulnerable consumers" is also mentioned, but its definition is again left up to each member state, although the Directives do established the fact that special measures need to be implemented to protect vulnerable consumers, including the prevention of disconnection from energy supply during critical times. In the European Economic and Social Committee's opinion on energy liberalization, the cross-sectorial nature of energy poverty is acknowledged (affecting the energy sector, health, consumer affairs and housing). In addition, it is proposed that a common general definition of energy poverty be adopted, which could later be adjusted to fit the specific context of each member state. It also proposes that a pan-European entity be establish that would monitor and measure the phenomenon [39]. It is likely that the increased awareness regarding energy poverty may be a result of the perceived risk of energy market liberalization. As observed in several countries around the world [12], this process can be associated with significant increases in energy prices-a key factor that contributes to the "development" of energy poverty.

Subsequently, a working paper by the European Commission proposes a preliminary definition for energy poverty, which can be described as "households that spend more than a pre-defined threshold share of their overall consumption expenditure on energy products", where the threshold seems to be "twice as high as the national average" ([21], p. 17). More recently, Directive 2012/27/EU [40] on energy efficiency refers to the establishment of energy efficiency obligation schemes as part of the 2020 Energy Strategy. The Directive explicitly mentions "a share of energy efficiency measures to be implemented as a priority in households affected by energy poverty", as well as the prevention of energy poverty.

Based on a series of interviews with specialists in Brussels, Bouzarovski, Petrova and Sarlamanovb [5] conclude that the apparent hesitance of dealing with energy poverty at an EU level is caused by several factors, such as the lack of a strong advocacy and initiative center, a lack of systematic scientific research on the topic and even the unwillingness of some member states to acknowledge the existence of fuel poverty within their territory.

Under these circumstances, direct policy measures that tackle energy poverty are being designed and implemented at a national and regional level. These include direct subsidies to limit the cost of energy services, special protection for low-income and "vulnerable consumers" against disconnection and the encouragement of energy efficiency investments by distributors through tradable white certificate schemes $[5,9,11]$. However, the most commonly implemented measure seems to consist of providing financial support for the rehabilitation of homes (usually quantified through an upgrade in the energy efficiency rating) [9]. The actual approach differs among countries, but the focus seems to be on providing a long term solution to energy poverty by eliminating what is most likely its key contributing factor.

Investments in improving the energy efficiency of the housing stock can have a three tiered long term direct benefit: lower costs of healthcare (putting less financial pressure patients and on national health systems), lower energy costs (generating additional disposable income that can be spent on products and services with a higher added-value than energy), and lower demand for imported fuels (slightly mitigating the issue of energy security). Moreover, indirect benefits can include a higher quality of life, increased productivity of human capital and reduction of greenhouse gas emissions. Emerging research suggests that the positive outcomes of such energy efficiency investments can be highly "profitable" from a net present value perspective [35].

It should be noted that, in order to maximize efficiency, the rehabilitation of the housing stock needs to target those dwellings that are most affected by energy poverty. In addition, adequate 
and consistent measuring of energy poverty at the national level is needed in order to evaluate the effectiveness of the policies.

\section{Measuring Fuel Poverty in the EU}

In the absence of a clear definition of "energy poverty" and "vulnerable consumers" (a term used in Directives by the European Parliament), a truly efficient set of policy measures to alleviate the problem cannot be designed nor implemented. Dubois [6] presents the integral role played by targeting and identification of energy poor households in the construction and application of policies. Thus, being able to define and measure the extent of the problem has been the focus of numerous and extensive studies. Given the complex nature of energy poverty issues, several approaches have been proposed and an ongoing debate seems to exist with regard to choosing the adequate indicators and methodology. These can be broadly classified into objective and subjective measures, with the former being constructed based on different definitions of energy poverty.

With regard to objective measures, Moore [7] and Heindl [41] provide evolutionary and comparative outlines of fuel poverty definitions, starting from the $10 \%$ expenditure on all energy services suggested by Boardman [2]. For the reasons stated in the previous sub-sections, this was later changed to account for the needed expenditure rather than the actual expenditure. In addition, some analyses also chose to assess household income both before housing costs as well as after (the logic being that housing costs, such as mortgage payments or rent, do not constitute income that can be spent elsewhere). Another adjustment that can be made to the measurement is to equivalise income according to household structure and size. This is done to reflect the fact that, for example, a couple with children needs to have a higher income compared to a couple without children in order to enjoy an equivalent standard of living. A distinct definition of fuel poverty presented by Moore [7] is based on "minimum income standards" (MIS) and states that a household is fuel poor if its residual net income (after housing costs and after all other minimum living costs (MIS)) is not sufficient to cover its required fuel costs.

Finally, as presented in Section 2.1, it is proposed that the UK government adopt a new indicator of energy poverty in the form defined by the Hills review: households are fuel poor if their required fuel costs are above the national median and if spending that amount would result in a residual income (after housing costs) that is below the official poverty line [25]. However, this definition remains controversial and the indicator may be revised before being used by policymakers [4,7,42]. Given the debates that exist among specialists regarding the approach best suited to measure energy poverty, several studies have made use of various definitions and compared the results from a structural (socio-demographics) and overall (total number of energy poor households) perspective [7,11,41].

Subjective measures of energy poverty refer to various methods of collecting self-assessments of whether households regard themselves as being affected by fuel poverty. This can be done, for example, by asking respondents whether they feel that they can afford to purchase energy services that satisfy all their heating, lighting and cooking needs or whether they feel that they are able to heat their homes adequately [43]. As with most questionnaire based surveys, this approach has its limitations. However, it does offer two distinct advantages compared to the objective measures. First, the results of such a study can be used to assess and compare energy poverty measurements across several countries without having to identify compatible data sources regarding patterns of household energy expenditure and income- as seen in the case of Eurostat's Statistics on Income and Living Conditions (SILC) surveys. Second, by combining a subjective approach with an objective measurement of the same population sample, it may be possible to identify households that feel fuel poor, but who do not spend a disproportionate amount on energy services because they are rationing their consumption [43]. Dubois [6] considers this type of fuel poor household to be particularly difficult to identify.

Bouzarovski [4] mentions a third type of approach based on actually monitoring the use of energy services in the home (light level, temperature, etc.) and comparing the values with a given standard. This type of measurement could be implemented using the "geographical identification as a proxy" approach presented by Dubois [6], which would require the collection of data from a sample 
of households within a similar set of dwellings from a distinct geographical unit (e.g., eight story panel apartment blocks built between 1960-1980 from a specific quarter of a city). The results could then be generalized to provide an approximate assessment of energy poverty within that geographical area. However, the practical difficulties of monitoring energy service use within the home mean that this method is likely the least feasible out of all options presented.

Finally, a high-level assessment of energy poverty at a national level could be performed based on multiple dimensions or an aggregated indicator that covers several macro indicators following the examples provided by Chester and Morris [12], Tirado Herrero and Bouzarovski [44] and Wang, Wang, $\mathrm{Li}$ and Wei [18]. Such assessments could be adjusted to make use of readily available statistics, but their accuracy may be limited.

\subsection{Proxy Indicators of Energy Poverty}

A report published for the benefit of the European Commission in 2015 by a European think tank provides a useful review of energy poverty and vulnerable energy consumer issues across the EU [36]. Building on the significant, but somewhat divergent body of research on the topic, the INSIGHT_E report provides a list of indicators that have been or that could be used in order to gauge the extent of the energy poverty phenomenon within EU member states.

The identified indicators are grouped into several categories:

- $\quad$ income (including data on the share of population at risk of poverty);

- energy consumption (the idea being that the amount and type of energy used by households can generate vulnerability especially in the face of price fluctuations);

- $\quad$ energy prices (including aspects related to how the energy markets function at the national level);

- tenure status and other housing characteristics (including type of dwelling and the use of central heating versus room heating systems); and

- well-being and material depravation (low quality housing, arrears on utility bills, inability to keep the home adequately warm or cold).

These indicators, while not directly identifying the phenomenon of energy poverty, represent components of its overall magnitude. Given the lack of clarity and uniformity in defining energy poverty (discussed in the previous section), some researchers have proposed using a combination of such proxy indicators in order to measure and compare energy poverty in a consistent way across various countries or regions $[44,45]$.

The method exemplified by Nussbaumer, Bazilian, Modi and Yumkella [45] would be preferred for a more accurate assessment. In this case, the authors decide on a set of proxy indicators to be used and assign a weight and a deprivation threshold for each. A large sample of the population is assessed individually and it is established whether a person can be identified as being energy poor or not. This method of multidimensional evaluation of individuals provides a more accurate image regarding fuel poverty at a national level compared to the compounding of macro indicators, such as "share of population at risk of poverty" and "share of population unable to maintain adequate warmth in the home". The latter is prone to errors caused by uncertainty regarding the size of the overlap between the various indicators (i.e., it is not clear whether a narrow share of the population is severely deprived or whether a larger share is moderately deprived).

However, the type of analysis performed by Nussbaumer, Bazilian, Modi and Yumkella [45] requires detailed data regarding the living conditions of individuals within the population across several countries. While it may be possible to implement a targeted large scale survey across the entire European Union in the future, the data required for the current analysis is not available. The best identified alternative given this context is exemplified by Tirado Herrero and Bouzarovski [44], who use three proxy indicators: percentage of people "unable to keep their homes adequately warm" (referred from now on as Not warm), "having arrears in utility bills" (Arrears) and "living in a home with a leaking roof, or the presence of damp and rot" (Leaks) in order to calculate a compound "Energy poverty index". 


\subsection{The Compound Energy Poverty Indicator (CEPI)}

In order to generate an assessment of energy poverty across all $28 \mathrm{EU}$ member states (as well as three other European countries) based on the indicators discussed by Pye, Dobbins, Baffert, Brajković, Grgurev, Miglio and Deane [36], we examined several potential data sources and decided to base our analysis on Eurostat in order to insure methodological consistency and to leverage its European focus. Several indicators were selected based on our research focus and grouped into two categories: EP indicators and EP pressure factors. The former will be included in a multidimensional indicator of $\mathrm{EP}$, while the latter will be discussed in the following subsection. Starting from the example of Tirado Herrero and Bouzarovski, we selected indicators related to arrears on utilities, poor dwelling quality and the self-assessed inability to maintain the home adequately warm. In addition, we identified two more variables that are also self-assessed and directly related to the conceptual definition of energy poverty by Bradshaw and Hutton [24], as quoted from in Section 2.1: "share of population living in a dwelling not comfortably cool during summer time" (referred as Not cool) and "share of population considering their dwelling as too dark" (Dark).

With regard to including Not Cool in the indicator, it is worth noting that its use does not mean that the absence of air conditioning or other heat mitigation solutions (shaded building, insulating materials, etc.) in hot places (e.g., Southern European countries) automatically indicates energy poverty. Because the Not cool measure is self-reported, it means that people are catalogued as having an increased level of energy poverty if they actually state that their home cannot be made comfortably cool. Thus, it may be that even in the absence of air conditioning or other heat mitigation solutions, people may feel healthy and reasonably comfortable during summer, meaning that they are not catalogued as energy poor. However, if their health or general well-being is affected by the inability to cool the home, then they are considered to be affected by EP to some extent (i.e., this is just one component of CEPI).

The next step in designing the indicator was to establish an adequate weighting for each component. Again, following the example provided by Tirado Herrero and Bouzarovski, we propose that the three self-assessed variables that refer to inadequate living conditions receive a total weight of 0.6 (of which Not warm 0.3, Not cool 0.2 and Dark 0.1) given their direct relationship with the conceptual definition of EP. A relatively higher weight is attributed to Not warm followed by Not cool because these are considered to be fundamental needs that need to be met by a dwelling in order to reduce mortality and morbidity rates among inhabitants in the short to medium term, while Dark is likely to have a significant impact in the medium to long term. The other two indicators, Arrears and Leaks, are considered to have a more indirect connection with EP and have been given a weight of 0.2 each. The weights were chosen so that $\sum_{i} w_{i}=1$.

A comparison between the proposed Compound Energy Poverty Indicator (CEPI) and the "Energy poverty index" of Tirado Herrero and Bouzarovski is presented in Table 1.

Table 1. Comparison between the Compound Energy Poverty Indicator (CEPI) and the Energy poverty index.

\begin{tabular}{|c|c|c|}
\hline Variable & CEPI Weight & Energy Poverty Index Weight \\
\hline Inadequate living conditions & 0.6 & 0.5 \\
\hline - Not warm & 0.3 & 0.5 \\
\hline - Not cool & 0.2 & - \\
\hline - Dark & 0.1 & - \\
\hline Arrears & 0.2 & 0.25 \\
\hline Leaks & 0.2 & 0.25 \\
\hline
\end{tabular}

Recognizing the somewhat subjective nature of our weighting approach, we emphasize that CEPI is only a conceptual proposal and the values assigned to each indicator are indicative. However, these were not arbitrarily assigned — as seen in Table 1, they follow a similar pattern compared to the Energy 
poverty index and were fine-tuned through a series of in-depth interviews on the topic of EP with five Romanian academics specialized in the study of poverty, sustainable development and human capital.

An ad-hoc sensitivity analysis was also performed, consisting in alternatively increasing/ decreasing the values of each weight by $10 \%$ and $20 \%$ in order to observe how the EU-28 CEPI value changes. The results showed a variation of the EU- 28 value between $-1 \%$ and $+1 \%$ in the $10 \%$ shift scenario and a $-2.1 \%$ to $+1.9 \%$ variation in the $20 \%$ shift scenario. This seems to indicate that the CEPI values are relatively robust and would change significantly only if a fundamental redesign of the indicator is made (i.e., assigning the highest weight to Arrears).

Thus, the proposed compound indicator is illustrated in Equation (1):

$$
\text { CEPI }=(0.3 \times \text { Not warm }+0.2 \times \text { Not cool }+0.1 \times \text { Dark }+0.2 \times \text { Arrears }+0.2 \times \text { Leaks }) \times 100
$$

The data for the five components was extracted from Eurostat [46] and covers all 28 EU member states, as well as Switzerland, Norway and Iceland. Given that the data for Not cool only covers the year 2012, this is the time of reference used for all other indicators. A more updated version of CEPI could be calculated provided new reliable data becomes available.

Figure 1 shows that Bulgaria is the country most affected by EP, while Sweden and Luxembourg are the EU members least affected. The EU-28 average is surpassed primarily by states from Southern and Eastern Europe. Due to the limitations specific to the method of compounding macro indicators (discussed in the previous subsection), the CEPI values should not be interpreted as "share of population affected by EP". However, we expect that any "share of population affected by EP" values would establish a similar order among the EU member states as seen in Figure 1.

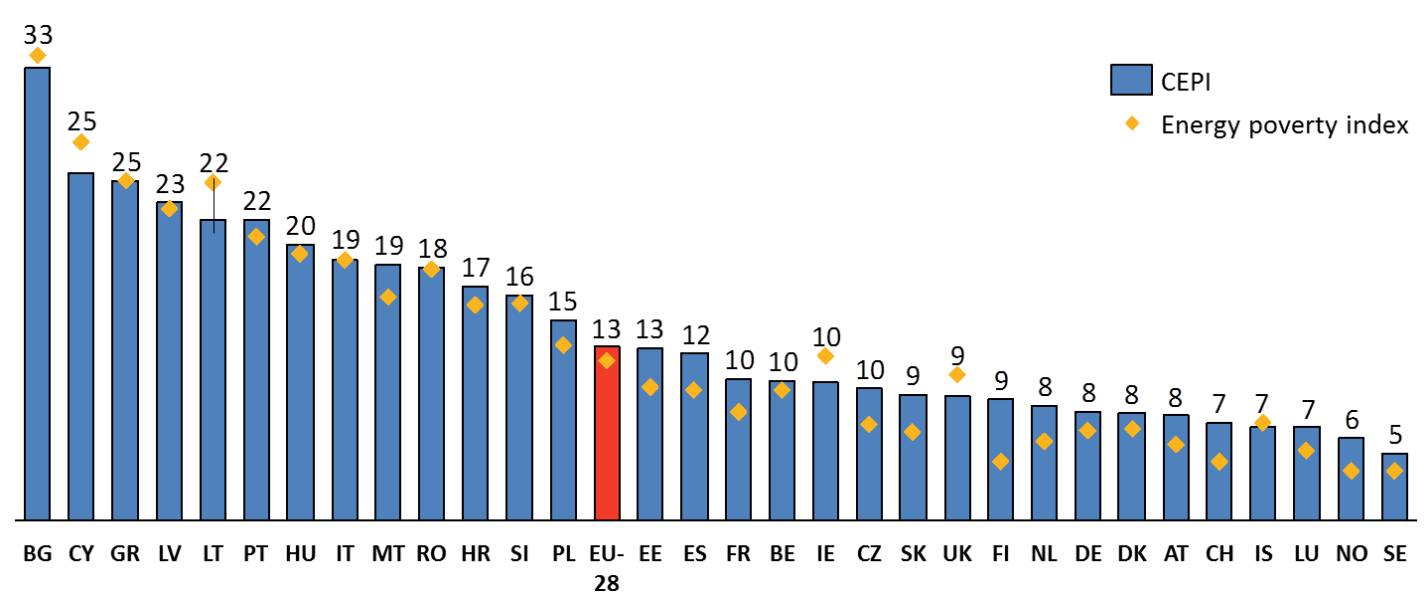

Figure 1. Compound Energy Poverty Indicator (compared to the Energy poverty index).

Given the similarities that exist between the two, the CEPI results do not differ significantly from the Energy poverty index (Figure 1 shows estimative results using data for the same year as CEPI). Notable differences above the EU-28 average consist only in Latvia and Lithuania and Malta and Romania, respectively, switching places within the hierarchy. When looking below the EU-28 average, several hierarchy changes can be observed, particularly in the case of Ireland, the United Kingdom and Finland. Bulgaria remains the most affected country and the gap between it and the following country (Cyprus) is significantly larger when CEPI is used. Sweden is indicated as the least affected country in the EU.

CEPI seeks to provide a standardized measurement of EP across Europe. However, the multitude of factors that determine the presence of this phenomenon and of nuances which influence its definition, some limitations need to be considered with regard to the results of the analysis. Firstly, applying a uniform weighting for Not cool and Not warm across all European countries can lead 
to an underestimation of EP in places where these components of CEPI have a lower impact on households. For example, maintaining a home comfortably cool during the summer in Ireland and the United Kingdom is an issue far less expensive to address compared to South European states. A similar logic can be applied in the case of Not warm in the latter category of countries. In order to compensate for this limitation, that the weighting of these variables could be differentiated among clusters of countries (e.g., South, North, and Central) or even individual states, depending on how relevant the problem is for the specific geographical region. In order to provide an objective adjustment of weights, this should be performed based on historical recorded temperatures (using a combination of average yearly temperature as well as high/low values, as recorded during summer/winter). Such an approach has not been identified in the existing literature and may produce different results compared to those seen in Figure 1.

Second, the CEPI weights do not directly consider the cost of resolving lighting, heating and cooling issues. It is clear that implementing an adequate heating solution for a household is far more expensive compared to resolving the issue of improper light. This issue is partly addressed by having a larger weight for Not warm and Not cool compared to Dark. However, the values could be further improved by taking into consideration the average life-cycle cost (acquisition, installation, maintenance, operation and dismantling/replacement over a set period of time, such as 40 years) of a heating, air conditioning and lighting solution for a home.

Finally, as discussed by Brunner, Spitzer and Christanell [19], EP can be difficult to identify in certain circumstances (e.g., when people try to avoid the stigma of being labeled as poor, when people have become accustomed to living in conditions that may be perceived as inadequate by the society in general, as well as other situations that depend on socio-cultural and psychological factors). Macro indicators and high-level data such as those included in CEPI cannot detect these specific situations. Thus, if a country has a low CEPI, it does not necessarily imply that the level of EP is very low or insignificant.

\subsection{CEPI Pressure Factors}

As mentioned above, our review of the Eurostat database based on the suggestions outlined by Pye, Dobbins, Baffert, Brajković, Grgurev, Miglio and Deane [36] has led to the identification of several variables that measure certain risks or pressure factors that could affect the evolution of the EP issue within a country. This section includes a more detailed description of these indicators and discusses the relationship that exists between them and CEPI. Finally, a CEPI prediction model based on these variables is provided.

\subsubsection{Selecting and Calculating the Pressure Factors}

After a survey of the existing literature on the topic, six variables were selected as EP pressure factors. Data on some of these is available directly from Eurostat, while others have been calculated based on several indicators or alternative data sources as well as researcher intuition. The current subsection provides a short description of each indicator and presents the approach used in their calculation or valuation.

\section{Tenure Status (Tenant)}

The indicator is based on the "Distribution of population by tenure status" provided by Eurostat. The total population is split into four categories that indicate what proportions (\% of the residents) are owners or tenants. This is considered to be an EP pressure factor due to the fact that tenants are very likely to lack the motivation to invest in improving the energy efficiency of their temporary home-leading to a higher than necessary consumption of energy and an increased risk of EP. In addition, the owners of rented dwellings are also unlikely to invest in energy efficiency improvements, unless these would allow them to generate more revenue from tenants. 
Aside from motivation, owners who have a mortgage on the property or tenants paying rent at market prices may lack the financial resources for home improvements compared to owners without mortgages and, respectively, tenants with reduced or free rent-further increasing EP risk. Taking into consideration the different risk levels determined by the tenure status (discussed above), we have assigned the following weights for each category of occupant:

- $\quad$ Tenant, rent at market price (\% of population) -1

- Tenant, rent at reduced price or free (\% of population) -0.7

- Owner, with mortgage or loan (\% of population) -0.2

- Owner, no outstanding mortgage or housing loan (\% of population) -0.1

Thus, the valuation of Tenant is based on a weighted average as presented in Equation (2):

Tenant $=(1 \times$ "Tenant, rent at market price" $+0.7 \times$ "Tenant, rent at reduced price or free" $+0.2 \times$ "Owner, with mortgage or loan" $+0.1 \times$ "Owner, no outstanding mortgage or housing loan")/2

Given that the sum of the four variables in Equation (2) is 100 (representing 100\% of the population), we chose to divide the weighting results by the sum of the weights $\left(\sum_{i} w_{i}=2\right)$. This maintains the indicator value in the 0-100 range for interpretation purposes.

Considering the valuation approach discussed above, we expect that a higher value of Tenant can be associated with a higher value of CEPI. Thus, the null hypothesis that we will seek to disprove is: "there is no correlation between Tenant and CEPI".

Type of Dwelling (Dwelling)

The indicator is based on the "Distribution of population by dwelling type" provided by Eurostat. The total population is split into four categories that indicate what proportions (\% of the residents) inhabit a certain type of dwelling. This is considered to be an EP pressure factor due to the expected higher heating/cooling cost associated with detached houses versus various types of grouped residences due to higher exposure to the environment (leading to lower thermal efficiency). Given the increased need for energy consumption of detached or semi-detached houses, the EP risk is considered to be higher compared to flats or other types of residences (which have a higher thermal efficiency). Thus, the indicator values are calculated using weights for the various types of dwellings, an approach similar to that presented for Tenant:

- $\quad$ Detached house-1

- $\quad$ Semi-detached house- 0.7

- Other (considered to be more similar to flats, but less efficient) -0.2

- Flat-0.1

Thus, the valuation of Tenant is based on a weighted average as presented in Equation (3):

$$
\begin{gathered}
\text { Dwelling }=(1 \times \text { "Detached house" }+0.7 \times \text { "Semi }- \text { detached house" } \\
+0.2 \times \text { "Other" }+0.1 \times \text { "Flat" }) / 2
\end{gathered}
$$

Given that the sum of the four variables in Equation (2) is 100 (representing 100\% of the population), we chose to divide the weighting results by the sum of the weights $\left(\sum_{i} w_{i}=2\right)$. This maintains the indicator value in the $0-100$ range for interpretation purposes.

Considering the valuation approach discussed above, we expect that a higher value of Dwelling can be associated with a higher value of CEPI. Thus, the null hypothesis that we will seek to invalidate is: "there is no correlation between Dwelling and CEPI". 
People at Risk of Poverty or Social Exclusion (RiskPov)

This indicator is based on the "People at risk of poverty or social exclusion" provided directly by Eurostat. It is used to assess one of the five headline targets of the "Europe 2020 headline indicators" (part of the Europe 2020 Strategy) and it is calculated by combining three specific social conditions: share of population at-risk-of-poverty after social transfers (income poverty), share of population that are severely materially deprived and share of population living in households with very low work intensity.

This indicator was selected as an EP pressure factor given the already established connection between "risk of poverty" and energy poverty [44]. We have opted for the broader "People at risk of poverty or social exclusion" indicator given its higher significance at the EU level一the target geography of the current study. With regard to interpretation, it is expected that a higher level of RiskPov is associated with a higher CEPI value. As was the case for the previous indicators, the null hypothesis that we will seek to disprove is: "there is no correlation between RiskPov and CEPI".

\section{Heating System Efficiency (RoomHeat)}

This indicator is based on the "Share of dwellings with central heating systems (collective and individual heating)" provided by Enerdata [47] as part of the ENTRANZE project (co-funded by the Intelligent Energy Europe Programme). The indicator groups dwellings into four groups, depending on the type of heating system that they employ: individual central heating, collective central heating (excluding district heat), district heating and room heating. Its selection as an EP pressure factor is based on the fact that central heating systems have a better energy efficiency compared to room heating.

In general, the most efficient form of central heating is considered to be district, followed by collective, although this is not always true, especially in some Eastern European countries, such as Romania [36]. Due to this issue and in order to preserve the objectivity of the indicator, weights were not assigned to differentiate between the four categories of heating systems. Instead, the analysis directly considers the share of dwellings that use room heating as being at risk of EP.

As there was no data available for three EU member states, the indicator values were calculated as an average for countries with a similar cultural and/or geographical context. Specifically, the value for Belgium was calculated as an average of room heating use in the Netherlands and Luxembourg, for Estonia we used Latvia and Lithuania and for Portugal we used Spain, Italy and Greece.

We expect that there is a direct relationship between RoomHeat and CEPI, meaning that the null hypothesis ("there is no correlation between RoomHeat and CEPI") would be disproved.

\section{Residential Consumption of Energy (Cons)}

This indicator is calculated as a ratio between the yearly residential consumption of energy (all forms of energy converted to Gigajoules) reported for each EU member state and the projected size of the population also reported by Eurostat at a country level. Initially, we sought to adjust the total population figure to better reflect residential population by taking into consideration various factors, including homelessness. However, the adjustments were not made due to the lack of reliable data as well as the limited significance of distorting factors (e.g., homelessness affects an estimated $0.01 \%-0.43 \%$ of the population according to Eurostat). As discussed by Pye, Dobbins, Baffert, Brajković, Grgurev, Miglio and Deane [36], a higher level of energy consumption increases household vulnerability to price increases and could thus be correlated to a higher risk of EP. The null hypothesis that we will seek to disprove is: "there is no correlation between Cons and CEPI".

\section{Affordability of Energy (Afford)}

This compound indicator represents an additional original contribution of the paper, with applications in research beyond the topic of energy poverty. It was included in the analysis in order to compare the national EP risk generated by residents not being able to purchase a sufficient 
amount of energy (either due to low incomes or high energy prices). Eurostat data show that electricity and gas are two forms of energy most frequently encountered in the EU for residential usage. Yearly and biannual price and consumption figures are available for each member state. The prices refer to average costs per unit of energy $(\mathrm{kWh})$ for an average household and include all taxes and levies in order to have a more accurate cross-country comparison from the perspective of the end user.

With regard to income, we have decided to use the mean equivalized net income per household. Equivalized incomes (also discussed in the previous sections) are frequently used in the study of energy poverty and are considered to provide a more accurate measure of household income. Both income and energy prices are expressed in Euros.

In order to calculate the affordability of energy, the mean equivalized net income per household is divided by the average price for one unit (kWh) of energy, as seen in Equation (4):

$$
\text { Afford }=\frac{\overline{I_{h}}}{\overline{P_{e n}}}
$$

where

$\mathrm{I}_{\mathrm{h}}=$ mean equivalized net income per household (Euro)

$\mathrm{P}_{\mathrm{en}}=$ average price for one unit of energy (Euro/ $\mathrm{kWh}$ )

The average energy price is calculated based on the average yearly prices for electricity and gas taking into consideration the share of each "fuel type" in the total residential consumption (see Equation (5)). The purpose of this adjustment is to avoid over or underestimation of the importance of gas or electricity prices within each member state's specific market.

$$
P_{e n}=r_{g a s} \times P_{g a s}+r_{e l} \times P_{e l}=\frac{\text { Cons gas }_{\text {gans }}}{\text { Congs }_{\text {gas }}+\text { Cons }_{e l}} \times P_{\text {gas }}+\frac{\text { Cons }_{e l}}{\text { Cons }_{g a s}+\text { Cons }_{e l}} \times P_{e l}
$$

where

$$
\begin{aligned}
& \mathrm{r}_{\text {gas/el }}=\text { share of gas/electricity in consumption } \\
& \text { Cons gas/el }=\text { consumption of electricity/gas }(\mathrm{kWh}) \\
& \mathrm{P}_{\text {gas/el }}=\text { price of electricity/gas (Euro/kWh) }
\end{aligned}
$$

The value of Afford shows how many units (kWh) of country specific energy an average household can afford to purchase in each EU member state. We expect that Afford is inversely correlated with CEPI in the sense that the less energy the average household can acquire, the higher the EP risk at the national level. The null hypothesis that we will seek to disprove is: "there is no correlation between Afford and CEPI".

We recognize that the weights for Tenant and Dwelling have been somewhat subjectively assigned (based on researcher intuition and motivated above). However, after testing several alternative valuations (maintaining the same hierarchy for the four categories) we have determined that the results of the econometric analysis are not significantly affected. With regard to the other four indicators, their values are objectively determined and thus are less exposed to reliability errors.

\subsubsection{Correlations between the Pressure Factors and CEPI}

Performing a correlation analysis is the first step in verifying the above mentioned null hypotheses regarding the relationship between CEPI and the six pressure factors and, subsequently, constructing the prediction model. The nature of the relationships observed between the indicators and CEPI (i.e., the relationship is monotonic, but non-linear) means that an analysis based on the Spearman coefficient should be used. Due to the fact that the year of reference for the CEPI components was 2012, the same year has been used to define the 28 member states across the six EP pressure factors. Table 2 illustrates the bivariate correlations between all the coefficients. 
Table 2. Bivariate correlation between CEPI and the pressure factors.

\begin{tabular}{cccccccc}
\hline & & Tenant & Dwelling & RiskPov & RoomHeat & Cons & Afford \\
\hline \multirow{2}{*}{ CEPI } & Spearman's rho & $-0.683^{*}$ & -0.180 & $0.810^{*}$ & $0.500^{*}$ & $-0.704^{*}$ & $-0.741^{*}$ \\
\cline { 2 - 8 } & $\mathrm{N}$ & 28 & 28 & 28 & 28 & 28 & 28 \\
\hline
\end{tabular}

* correlation significant at the 0.01 level.

As seen in Table 2, a strong and significant correlation exists between CEPI and most of the identified pressure factors. In the case of Dwelling, a correlation with CEPI cannot be identified. This suggests that the type of dwelling that people live in (detached house, semi-detached house, and flat) does not determine an increased risk of energy poverty.

The significant correlations identified between CEPI and RiskPov, RoomHeat and Afford respectively are in line with our expectations and with the ideas expressed by other researchers, which were presented and discussed in previous sections. According to Pallant [48], the statistical significance of the correlation depends on the sample size, with a higher risk that strong correlations may not be significant when a small sample size exists (<30 cases). Given that the analysis only looks at the 28 member states for a single year, it is noteworthy that these three correlations are significant at a very low level of $p$.

The negative correlation between Cons and CEPI means that a high level of energy consumption per capita can be associated with a lower intensity of energy poverty. This suggests that, while an increased level of price vulnerability may exist for households consuming a large amount of energy, higher levels of consumption per capita are specific to those countries less affected by EP. Thus, Cons cannot be used as a predictor variable, but it can indicate an EP risk for income poor households in low EP countries. For example, in Finland, a country with a high energy consumption per capita, the proportion of income poor people suffering from cold homes and arrears on utilities is two times higher compared to the overall population (three times higher in the case of Norway) [46], and it is these people who are most vulnerable in the face of energy price instability.

The negative correlation between Tenant and CEPI is also counterintuitive and suggests that EP is higher in countries where the share of population that rents homes is low. After further exploring this issue, we have determined that a geographical clustering exists within the CEPI-Tenant relationship in the sense that countries from Southern and Eastern Europe (for the purpose of this analysis, "Eastern Europe" includes those countries which were part of the USSR or under its sphere of influence) tend to have both a lower Tenant score and a higher CEPI score. An illustration of the clustering is provided in Figure 2.

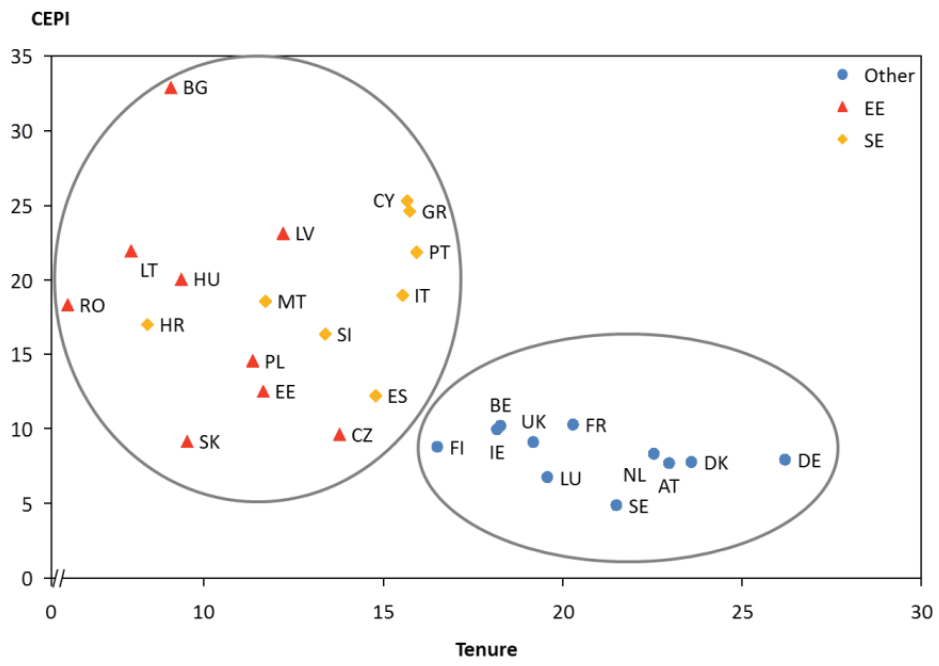

Figure 2. Correlation between CEPI and Tenure with geographical clusters. 
These results suggest that the tenure status of the population can be correlated to a specific of socioeconomic context that exists in Southern and Eastern European countries. Our preliminary analysis suggests that material depravation and generally unfavorable economic conditions can be correlated to a higher percentage of the population being owners and not tenants. Thus, it is likely that the connection between CEPI and Tenant may be caused by a third variable. In the case of Southern European states, this may be related to the economic crisis and the associated long term effect of the housing market bubble. The data illustrate the situation that existed in 2012, a period (along with 2013) with the highest recorded unemployment rates since 2002 in Southern Europe [46], putting pressure on the ability of households to afford paying mortgages in the years to come. The full implications of the relationships that exist between these variables should be explored in future research.

A partial correlation analysis shows that the null hypothesis of "no correlation between CEPI and Tenant" cannot be disproved when controlling for the share of the population affected by "severe material depravation" (Depravation), as seen in Table 3. Given that the latter indicator is one of the three components included in the methodology through which RiskPov is calculated, it is clear that Tenant cannot be included in the modeling.

Table 3. Partial correlation between CEPI and Tenant controlling for Depravation.

\begin{tabular}{ccc}
\hline Control Variable: Depravation & Tenant \\
\hline \multirow{2}{*}{ CEPI } & Correlation & -0.098 \\
& Significance (2-tailed) & 0.626 \\
\hline
\end{tabular}

\subsubsection{CEPI Pressure Factor Model Iterations}

The CEPI forecasting model uses a multiple linear regression to establish to what extent and how energy poverty (as determined by CEPI) can be explained and determined based on the discussed pressure factors. However, some of the predictor variables will need to be eliminated in order to meet the requirements specific to the chosen regression model.

As seen in the previous subsection, Dwelling cannot be included in the analysis, as it does not correlate significantly with the dependent variable. In addition, Tenant has also been eliminated, as discussed above. This leaves RiskPov, Afford, RoomHeat and Cons as potential predictors within the model.

After conducting preliminary analyses to ensure that the assumptions of the regression model are not violated, the initial model iteration included all four variables. The resulting model explains $75.3 \%$ of the variance of CEPI, $F(4,23)=17.55, p<0.001$. Within the model, only RiskPov was statistically significant (beta $=0.61 p<0.001$ ). This could be partially explained by the small sample size ( $N=28$ - the EU member states), which does not meet the recommendation of having at least 15 cases for each independent variable [49].

The sample size issue could be addressed by reducing the number of predictors. This means that at least two of the indicators would need to be excluded from the model (in order to reach a minimum sample requirement of 30 ).

After running a series of iterations with all possible combinations, the best alternative model identified explains $71.2 \%$ of the variance in CEPI, $F(2,25)=30.94, p<0.001$ and includes two predictors, both of which are statistically significant: RiskPov (beta $=0.68, p<0.001$ ) and Afford (beta $=-0.25$, $p=0.068$ ). Table 4 provides a comparative illustration of the two models discussed above.

Based on the results of the analysis, we consider that the reduced model represents the safer option with regard to forecasting CEPI and predicting the size and direction of the impact of possible pressure factors. In addition, the change in $\mathrm{R}^{2}$ between the two is not very large. However, the full model is more likely to provide useful insights into which macro indicators can be used to study or even predict risks and trends in the evolution of the energy poverty issue at a national and regional level. 
Table 4. CEPI pressure factor regression models.

\begin{tabular}{|c|c|c|c|c|c|c|c|c|c|c|}
\hline & \multicolumn{5}{|c|}{ Full Model } & \multicolumn{5}{|c|}{ Reduced Model } \\
\hline & \multicolumn{3}{|c|}{ Coefficients } & \multirow{3}{*}{$t$} & \multirow{3}{*}{$p$} & \multicolumn{3}{|c|}{ Coefficients } & \multirow{3}{*}{$t$} & \multirow{3}{*}{$p$} \\
\hline & \multicolumn{2}{|c|}{ Unstandardized } & \multirow{2}{*}{$\begin{array}{c}\text { Standardized } \\
\text { Beta }\end{array}$} & & & \multicolumn{2}{|c|}{ Unstandardized } & \multirow{2}{*}{$\frac{\text { Standardized }}{\text { Beta }}$} & & \\
\hline & B & $\begin{array}{c}\text { Std. } \\
\text { Error }\end{array}$ & & & & B & $\begin{array}{c}\text { Std. } \\
\text { Error }\end{array}$ & & & \\
\hline (constant) & 6.97 & 4.92 & & 1.42 & 0.17 & 2.51 & 3.77 & & 0.67 & 0.51 \\
\hline RiskPov & 0.52 & 0.11 & 0.61 & 4.73 & 0.00 & 0.57 & 0.11 & 0.68 & 5.25 & 0.00 \\
\hline Afford & -0.01 & 0.01 & -0.13 & -0.89 & 0.38 & -0.02 & 0.01 & -0.25 & -1.91 & 0.07 \\
\hline RoomHeat & 0.02 & 0.03 & 0.07 & 0.57 & 0.57 & & & & & \\
\hline \multirow[t]{2}{*}{ Cons } & -0.20 & 0.12 & -0.23 & -1.66 & 0.11 & & & & & \\
\hline & \multicolumn{5}{|c|}{$R^{2}=.753 ; F(4,23)=17.55, p<0.001$} & \multicolumn{5}{|c|}{$R^{2}=0.712 ; F(2,25)=30.94, p<0.001$} \\
\hline
\end{tabular}

\section{Discussion and Conclusions}

Energy poverty, or the inability of households to afford adequate access to energy services, is an issue that can have a significant effect on the quality of life and even the state of health of individuals or households. A thermally inefficient housing stock, low incomes and rising energy prices have increased the severity of this problem in high and middle income countries.

Extensive studies on the topic, as well as abatement policies, exist in the United Kingdom and the Republic of Ireland-the countries from which key proponents and researchers in this field originate. However, there is a limited understanding of energy poverty at the EU level, in spite of growing public and institutional awareness. The lack of systematic research and standardized definitions and methodologies has made it difficult to assess the severity of the problem. Without a structural understanding of the issue, its determinants and its impact, the policies meant to alleviate it are likely to have a limited efficiency.

The aim of our research was to generate a renewed discussion on the topic of energy poverty at the EU level, but also an improved energy poverty indicator. Moreover, the paper has looked into some possible factors that can put pressure on an existing situation of energy poverty.

Given that several European states are attempting to assess the severity of the issue and address it by providing support to those most affected, our initial focus was set on designing an instrument that can help in this regard. The result was the Compound Energy Poverty Indicator. This tool builds upon existing research, but provides a more complete and complex evaluation of energy poverty at the national level. The results revealed that the hierarchy of energy poverty illustrated by (Tirado Herrero and Bouzarovski [44]) remains somewhat stable, but is finely adjusted through the inclusion of additional indicators of inadequate living conditions. Eastern European, as well as some Southern, EU member states are the most affected by energy poverty, while countries like Sweden, Luxembourg, Norway and Austria are the least affected. While providing a standardized measurement of energy poverty across Europe, CEPI does have some limitations that need to be taken into consideration, such as not being able to account for 'hidden' incidences of energy poverty and using a standard weight for the lack of adequate cooling/heating irrespective of the specific national climate.

In the second part of the quantitative analysis, CEPI is included as a dependent variable in an econometric model, so as to better grasp some of the variables that act as pressure factors for energy poverty, such as risk of poverty and social exclusion, efficiency of heating systems, total consumption of energy per household and rising energy prices. The analysis produces two models that indicate the strength and direction of the pressure that these factors tend to have on energy poverty.

The current work extends and improves the existing research on the topic by: providing an explicit image of energy poverty (as determined by the proposed CEPI) for every EU member state, proposing a prediction model of energy poverty based on specific pressure factors and computing a compound indicator that is able to express the average affordability of energy at the national level (with 
applications in other types of cross-country comparisons). The results of the research are expected to be relevant for national and EU policymakers who must deal in practice with the issue of energy poverty (as it offers insights into the structure and severity of this issue within the European Union).

As future directions for the research, we aim to identify and study regional differences that impact energy poverty across Europe. We will also seek to develop both CEPI and the pressure factor model. With regard to CEPI, we will further test and refine the indicator design (using the weight adjustment measures discussed in Section 3.2 and through a comprehensive survey of energy poverty specialists). We will also seek to provide a pan European mapping of the phenomenon and its evolution over the years. With regard to the model, the goal is to determine additional factors that prove to have a certain pressure on the energy poverty phenomenon, thus promoting sustainable development across the EU.

Acknowledgments: This work has been partly supported through the UAIC Grant for Young Researchers competition of the Alexandru Ioan Cuza University of Iaşi, Romania (Grant registration number: GI-2015-15). The POSCCE O 2.2.1, SMIS-CSNR 13984-901, No. 257/28.09.2010 Project, CERNESIM, is also gratefully acknowledged for the infrastructure used in this work. The authors are also grateful for the valuable feedback offered by the anonymous reviewers of the paper.

Author Contributions: The authors' contributions were equal. Alexandru Maxim, Costică Mihai and Constantin-Marius Apostoaie reviewed the literature, designed the research, performed the analysis and drew conclusions. Ionel Bostan reviewed the literature, discussed the data and the analysis and edited the paper. Cristian Popescu and Costel Istrate collected and discussed the data and the analysis and performed the paper editing. All authors have read and approved the final manuscript.

Conflicts of Interest: The authors declare no conflict of interest.

\section{References}

1. Liddell, C.; Morris, C.; McKenzie, S.J.P.; Rae, G. Measuring and monitoring fuel poverty in the UK: National and regional perspectives. Energy Policy 2012, 49, 27-32. [CrossRef]

2. Boardman, B. Fuel Poverty: From Cold Homes to Affordable Warmth; Belhaven Press: London, UK, 1991.

3. MacKerron, G. Foreword. Energy Policy 2012, 49, 1. [CrossRef]

4. Bouzarovski, S. Energy poverty in the European Union: Landscapes of vulnerability. Wiley Interdiscip. Rev. Energy Environ. 2014, 3, 276-289. [CrossRef]

5. Bouzarovski, S.; Petrova, S.; Sarlamanovb, R. Energy poverty policies in the EU: A critical perspective. Energy Policy 2012, 49, 76-82. [CrossRef]

6. Dubois, U. From targeting to implementation: The role of identification of fuel poor households. Energy Policy 2012, 49, 107-115. [CrossRef]

7. Moore, R. Definitions of fuel poverty: Implications for policy. Energy Policy 2012, 49, 19-26. [CrossRef]

8. Pickvance, K. Book review: Energy poverty in Eastern Europe: Hidden geographies of deprivation by stefan buzar, 2007. Urban Stud. 2009, 46, 974-976. [CrossRef]

9. UNDP Romania. Improving Energy Efficiency in Low-Income Households and Communities in Romania. Available online: http://www.undp.ro/projects.php?project_id=63 (accessed on 11 May 2015).

10. Poputoaia, D.; Bouzarovski, S. Regulating district heating in Romania: Legislative challenges and energy efficiency barriers. Energy Policy 2010, 38, 3820-3829. [CrossRef]

11. Herrero, S.T.; Ürge-Vorsatz, D. Trapped in the heat: A post-communist type of fuel poverty. Energy Policy 2012, 49, 60-68. [CrossRef]

12. Chester, L.; Morris, A. A new form of energy poverty is the hallmark of liberalised energy sectors. Aust. J. Soc. Issues 2012, 46, 435-459.

13. Farré, P.P.; García, C.M.; Hervitz, H.M. Deregulation and liberalization in the European electricity sector. Int. Bus. Econ. Res. J. 2010, 9, 129-134. [CrossRef]

14. Percebois, J. Electricity liberalization in the European Union: Balancing benefits and risks. Energy J. 2008, 29, 1-19. [CrossRef]

15. Atanasiu, B.; Kontonasiou, E.; Mariottini, F. Alleviating Fuel Poverty in the EU: Investing in Home Renovation, a Sustainable and Inclusive Solution; BIPE: Brussels, Belgium, 2014.

16. González-Eguino, M. Energy poverty: An overview. Renew. Sustain. Energy Rev. 2015, 47, 377-385. [CrossRef] 
17. International Energy Agency (IEA). World Energy Outlook 2007-Focus on Energy Poverty; IEA: Paris, France, 2007.

18. Wang, K.; Wang, Y.-X.; Li, K.; Wei, Y.-M. Energy poverty in China: An index based comprehensive evaluation. Renew. Sustain. Energy Rev. 2015, 47, 308-323. [CrossRef]

19. Brunner, K.-M.; Spitzer, M.; Christanell, A. Experiencing fuel poverty. Coping strategies of low-income households in Vienna/Austria. Energy Policy 2012, 49, 53-59. [CrossRef]

20. The World Bank. World Development Indicators \& Global Development Finance; The World Bank: Washington, DC, USA, 2015.

21. European Commission. An Energy Policy for Consumers; European Commission: Brussels, Belgium, 2010.

22. Isherwood, B.C.; Hancock, R.M. Household Expenditure on Fuel: Distributional Aspects; Economic Adviser's Office, DHSS: London, UK, 1979.

23. Osbaldeston, J. Fuel poverty in UK cities. Cities 1984, 1, 366-373. [CrossRef]

24. Bradshaw, J.; Hutton, S. Social policy options and fuel poverty. J. Econ. Psychol. 1983, 3, 249-266. [CrossRef]

25. Hills, J. Getting the Measure of Fuel Poverty: Final Report of the Fuel Poverty Review; Centre for the Analysis of Social Exclusion: London, UK, 2012.

26. Fatona, P.; Abiodun, A.; Olumide, A.; Adeola, A.; Abiodun, O. Viewing energy, poverty and sustainability in developing countries through a gender lens. In New Developments in Renewable Energy; Arman, $\mathrm{H}$., Yuksel, I., Eds.; InTech: Rijeka, Croatia, 2013.

27. Hui, S.C.M. From renewable energy to sustainability: The challenge for Hong Kong. In Proceedings of the POLMET ‘97 Conference, Hong Kong, China, 25-27 November 1997; pp. 351-358.

28. Pires Manso, J.R.; Behmiri, N.B. Renewable energy and sustainable development. Estud. Econ. Apl. 2013, 31, 7-34.

29. Sarvan, E.; Schiessler, N.; Eldridge, J.; Jones, W. Life and Energy, Innovative Solutions for Sustainable and Efficient Energy in Europe; European Communities: Brussels, Belgium, 2007.

30. Markandya, A.; Arto, I.; González-Eguino, M.; Román, M.V. Towards a green energy economy? Tracking the employment effects of low-carbon technologies in the European Union. Appl. Energy 2016, in press. [CrossRef]

31. European Foundation for the Improvement of Living and Working Conditions. Greening of Industries in the EU: Anticipating and Managing the Effects on Quantity and Quality of Jobs; Eurofund: Dublin, Ireland, 2012.

32. Rudge, J. Coal fires, fresh air and the hardy British: A historical view of domestic energy efficiency and thermal comfort in Britain. Energy Policy 2012, 49, 6-11. [CrossRef]

33. Braubach, M.; Jacobs, D.; Ormandy, D. Environmental Burden of Disease Associated with Inadequate Housing; World Health Organization: Copenhagen, Danmark, 2011.

34. Liddell, C. Fuel poverty comes of age: Commemorating 21 years of research and policy. Energy Policy 2012, 49, 2-5. [CrossRef]

35. Ormandy, D.; Ezratty, V. Health and thermal comfort: From who guidance to housing strategies. Energy Policy 2012, 49, 116-121. [CrossRef]

36. Pye, S.; Dobbins, A.; Baffert, C.; Brajković, J.; Grgurev, I.; Miglio, R.D.; Deane, P. Energy Poverty and Vulnerable Consumers in the Energy Sector across the EU: Analysis of Policies and Measures; INSIGHT_E: Brussels, Belgium, 2015.

37. European Parliament, European Council. Directive 2009/72/EC of the European Parliament and of the Council of 13 July 2009 concerning common rules for the internal market in electricity and repealing Directive 2003/54/EC. Off. J. Eur. Union 2009, L 211, 55-93.

38. European Parliament, European Council. Directive 2009/73/EC of the European Parliament and of the Council of 13 July 2009 concerning common rules for the internal market in natural gas and repealing Directive 2003/55/EC. Off. J. Eur. Union 2009, L 211, 94-136.

39. European Economic and Social Committee. Opinion of the European Economic and Social Committee on Energy Poverty in the Context of Liberalisation and the Economic Crisis; European Economic and Social Committee: Brussels, Belgium, 2010.

40. European Parliament, European Council. Directive 2012/27/EU of the European Parliament and of the Council of 25 October 2012 on energy efficiency, amending Directives 2009/125/EC and 2010/30/EU and repealing Directives 2004/8/EC and 2006/32/EC. Off. J. Eur. Union 2012, L 315, 1-56. 
41. Heindl, P. Measuring Fuel Poverty: General Considerations and Application to German Household. ZEW Discuss. Pap. 2013, 13, 1-32. [CrossRef]

42. ACE; CSE; Moore, R. Improving the Hills Approach to Measuring Fuel Poverty; Association for the Conservation of Energy: London, UK, 2012.

43. Waddams Price, C.; Brazier, K.; Wang, W. Objective and subjective measures of fuel poverty. Energy Policy 2012, 49, 33-39. [CrossRef]

44. Tirado Herrero, S.; Bouzarovski, S. Energy Transitions and Regional Inequalities in Energy Poverty Trends: Exploring the EU Energy Divide. USAEE Work. Pap. 2014, 14, 1-45.

45. Nussbaumer, P.; Bazilian, M.; Modi, V.; Yumkella, K.K. Measuring energy poverty: Focusing on what matters. In Oxford Poverty \& Human Development Initiative (OPHI); Working Paper No. 42; University of Oxford: Oxford, UK, 2011.

46. Eurostat. Eurostat Database. Available online: http://ec.europa.eu/eurostat/data/database (accessed on 28 March 2016).

47. Enerdata. Entranze. Available online: http:/ /www.entranze.enerdata.eu/ (accessed on 28 March 2016).

48. Pallant, J. SPSS Survival Manual: A Step by Step Guide to Data Analysis Using SPSS, 4th ed.; Allen \& Unwin: Crows Nest, Australia, 2011; p. 345.

49. Stevens, J. Applied Multivariate Statistics for the Social Sciences, 3rd ed.; Lawrence Erlbaum: Mahwah, NJ, USA, 1996.

(C) 2016 by the authors; licensee MDPI, Basel, Switzerland. This article is an open access article distributed under the terms and conditions of the Creative Commons Attribution (CC-BY) license (http://creativecommons.org/licenses/by/4.0/). 